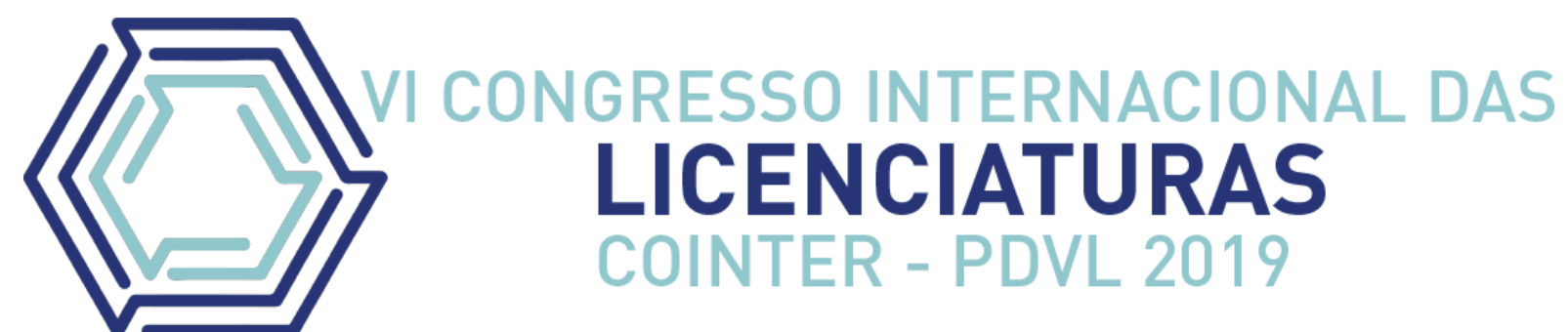

\title{
SERPENTES E ACIDENTES OFÍDICOS: ANÁLISE DE CONTEÚDOS E IMAGENS EM LIVROS DIDÁTICOS DE BIOLOGIA DO ENSINO MÉDIO
}

\author{
SERPIENTES Y ACCIDENTES OFIDIOS: ANÁLISIS DE CONTENIDOS E \\ IMÁGENES EN LIBROS DE BIOLOGÍA DE LA ESCUELA SECUNDARIA
SNAKES AND OPHIDIANS ACCIDENTS: ANALYSIS OF CONTENTS AND IMAGES IN HIGH SCHOOL BIOLOGY TEXTBOOKS

\author{
Apresentação: Comunicação Oral \\ Anderson Pimentel dos Santos ${ }^{1}$; Jeanne Claine de Albuquerque Modesto ${ }^{2}$. \\ DOI: https://doi.org/10.31692/2358-9728.VICOINTERPDVL.2019.0057
}

\begin{abstract}
Resumo
Os livros didáticos representam um dos recursos didáticos mais utilizados tanto por professores no preparo de suas aulas, como também uma fonte de pesquisa para os alunos. Essa importância aumenta em locais onde o livro é um dos ou o único recurso didático disponível. A presença do conteúdo sobre serpentes e acidentes ofídicos no livro de biologia, quando apresentado de forma correta, pode ajudar na diminuição do número de acidentes e óbitos por serpentes, visto que a melhor forma de prevenção é através do conhecimento. $\mathrm{O}$ objetivo deste presente trabalho foi realizar uma análise crítica de como é abordado o conteúdo de serpentes e acidentes ofídicos nos livros didáticos de biologia do ensino médio aprovados pelo PNLD para o triênio 2018-2020. Os livros foram analisados através de uma série de critérios pré-estabelecidos, sendo cada critério considerado como ausente ou presente. Também foi feita a análise e a categorização das imagens referentes a estes animais nos livros, incluindo sua funcionalidade, relação com o texto principal e presença de etiquetas verbais. Nos livros analisados é possível observar que nem sempre o conteúdo é abordado de forma satisfatória e, em alguns deles, é possível notar ainda a presença de equívocos conceituais. Em apenas dois livros das coleções analisadas o conteúdo foi abordado de forma considerada satisfatória. Em conclusão, partindo da importância da biologia no currículo escolar e dos livros didáticos na formação dos alunos, consideramos que o conteúdo sobre acidentes ofídicos nos livros didáticos precisa receber uma maior atenção por parte dos autores.
\end{abstract}

Palavras-Chave: Livro didático, Acidentes ofídicos, Serpentes, PNLD.

\section{Resumen}

1 Licenciatura em Ciências Biológicas, UFPE, anderson.pimentel.eb@hotmail.com;

2 Professora Associada do Centro Acadêmico de Vitória, UFPE, jeanne.modesto@ufpe.br. 
Los libros de texto representan uno de los recursos de enseñanza más utilizados por los maestros para preparar sus clases, así como una fuente de investigación para los estudiantes. Esta importancia aumenta en los lugares donde el libro es uno de los únicos recursos didácticos disponibles. La presencia de contenido de serpientes y ofídios de serpientes en el libro de texto de biología, cuando se presenta adecuadamente, puede ayudar a reducir la cantidad de accidentes y muertes por ofídios de serpientes, ya que es mejor prevenir el conocimiento. El objetivo de este documento era realizar un análisis crítico de cómo se aborda el contenido de las serpientes y los accidentes ofídicos de serpiente en los libros de texto de biología de la escuela secundaria aprobados por PNLD para el período 2018-2020. Los libros se analizaron utilizando una serie de criterios preestablecidos, cada uno de los cuales se considera ausente o presente. También se realizó el análisis y categorización de las imágenes relacionadas con estos animales en los libros, incluida su funcionalidad, relación con el texto principal y la presencia de etiquetas verbales. En los libros analizados es posible observar que el contenido no siempre se aborda satisfactoriamente y, en algunos de ellos, también es posible notar la presencia de errores conceptuales. En solo dos libros de las colecciones analizadas, el contenido se consideró satisfactoriamente. En conclusión, con base en la importancia de la biología en el currículo escolar y los libros de texto en la educación de los estudiantes, consideramos que el contenido sobre accidentes de mordeduras de serpientes en los libros de texto debe recibir mayor atención de los autores.

Palabras Clave: Libro de texto, accidentes de serpientes, serpientes, PNLD.

\begin{abstract}
The textbooks pose one of the most widely used teaching resources for teachers in preparing their classes, as well as a source of research for students. This importance increases in places where the book is one of or the only teaching resources available. The presence of snake and ophidians content in the biology textbook, when properly presented, can help to decrease the number of ophidians accidents and deaths, as knowledge is best prevented. The objective of this study was to conduct a review of how it addressed the content of snakes and ophidians in textbooks of high school biology approved by PNLD for the triennium 2018-2020. The books were analyzed using a series of pre-established criteria, each criterion being considered absent or present. The analysis and categorization of the images related to these animals in the books was also performed, including their functionality, relation to the main text and presence of verbal labels. In the analyzed books it is possible to note that the content is not always satisfactorily approached and, in some of them, it is also possible to notice the presence of conceptual mistakes. In only two books of the collections analyzed the content was considered satisfactorily. In conclusion, based on the importance of biology in the school curriculum and textbooks in student education, we consider that the content about snakebite accidents in textbooks needs to receive greater attention from the authors.
\end{abstract}

Keywords: Textbook, Ophidians Accidents, Snakes, PNLD.

\title{
Introdução
}

Embora existam atualmente diversos recursos didáticos inseridos no ambiente escolar 
como, por exemplo, jogos didáticos, filmes, músicas, apresentações em power point, além é claro da internet por meio de sites, vídeo aulas e aplicativos de celular que possam ser utilizados durante as aulas (NICOLA; PANIZ, 2016), o livro didático (LD) ainda continua sendo uns dos recursos indispensáveis, tanto por parte dos professores no preparo de suas aulas como para os alunos como uma fonte de informação para realização de pesquisas e consultas em geral (FRACALANZA; MEGID NETO, 2006; SANTOS, 2018).

Segundo Sadrin, Puorto e Nardi (2005), alguns pontos favorecem para que o LD tenha esse papel de destaque frente aos outros recursos, entre eles destacam-se o grande potencial que o livro tem de transmitir as informações e sua fácil utilização por parte dos professores e alunos no seu dia a dia. Com essa posição de destaque dos livros didáticos e seu poder de disseminação da informação, Sadrin, Puorto e Nardi (2005) ressaltam ainda a importância das críticas e das preocupações de alguns especialistas sobre a qualidade desses livros, uma vez que conteúdos errados podem ser repassados para os alunos e assim virarem verdades incontestáveis. Além disso, segundo Lajolo (1996), o LD apresenta um baixo custo e não necessita de manutenções como no caso dos recursos tecnológicos. Podemos ainda acrescentar que o LD pode ser reutilizado por vários anos a depender do seu estado de conservação e também de seu ano de publicação.

O livro didático, sendo um grande disseminador de informações e tendo uma grande relevância no ambiente escolar, logo se torna uma fonte importante de transmissão de conteúdos, principalmente em escolas onde ele é um dos ou o único meio de apoio pedagógico tanto para professores quanto para alunos, como relatado por Nuñez et al (2001). Esta transmissão de conteúdos, quando feita de forma correta e satisfatória, tem sua importância ainda mais destacada quando envolve temas relacionados à saúde humana como, por exemplo, acidentes por animais peçonhentos. Segundo Guimarães (2010), uma das possíveis causas de acidentes por esses animais é a desinformação, levando em consideração que o desconhecimento pode levar o indivíduo a se aproximar destes animais, seja na tentativa de afastá-los ou de matá-los, ou até mesmo por brincadeira ou curiosidade, como no caso das crianças.

São considerados animais peçonhentos aqueles que possuem glândulas produtoras de veneno ligadas a um aparato inoculador, sendo este especialmente desenvolvido para injetar o veneno dentro do corpo de outro animal, seja por defesa quando se sentem ameaçados ou visando à obtenção de presa para alimentação. $\mathrm{O}$ aparato inoculador pode ser composto por 
dentes, quelíceras, ferrões entre outros, já o veneno produzido pelas glândulas pode também ser chamado de peçonha (FREITAS; SILVA, 2006; SANTOS, 2018). Dentre os principais animais peçonhentos de importância médica no Brasil, as serpentes se destacam tanto pelo número de acidentes causados como pelos sentimentos despertados na população em geral, como repulsa e medo. Embora no Brasil existam aproximadamente 405 espécies de serpentes distribuídas em 10 famílias (COSTA; BÉRNILS, 2018), apenas duas dessas famílias são consideradas de importância médica, sendo elas: Viperidae e Elapidae. Todas as espécies pertencentes a estas famílias são peçonhentas e o acidente pode evoluir para quadros graves e levar o indivíduo a morte. Logo, uma abordagem eficiente sobre o tema serpentes e acidentes ofídicos nos livros didáticos pode ajudar a população na identificação daqueles gêneros que oferecem riscos à saúde, na prevenção de acidentes e também no manejo das possíveis vítimas.

Em trabalhos anteriores, envolvendo a temática de serpentes e acidentes ofídicos em livros didáticos, diversos autores relataram a permanência de equívocos conceituais relacionados ao tema, além de considerarem o conteúdo ainda insatisfatório (SANDRIN; PUORTO; NARDI, 2005; SILVA; BOCHNER; GIMÉNEZ, 2011; BORGES; OLIVEIRA; COSTA, 2003; BERGMANN; DOMINGUINI, 2015). Levando em consideração o grande número de caso de acidentes por serpentes em todo o Brasil e a importância que o livro didático tem no ambiente escolar, como uma significativa fonte de propagação de informações, esse trabalho tem por objetivo analisar como o conteúdo sobre serpentes peçonhentas é abordado nos livros do ensino médio de biologia aprovados pelo Plano Nacional do Livro Didático (PNLD) para o triênio 2018-2020 e já em uso nas escolas.

\section{Fundamentação Teórica}

\section{Serpentes e Acidentes Ofídicos}

Os acidentes causados por serpentes são chamados de ofidismo. Em 2018, segundo o Ministério da Saúde, o número de acidentes ofídicos documentados chegou a 28.841 casos (BRASIL, 2019a), enquanto que o número de óbitos foi de 106 casos (BRASIL, 2019b). Como citado anteriormente, apenas duas famílias de serpentes são consideradas de importância médica no Brasil, sendo elas: Viperidae e Elapidae. Dentro da família Viperidae, são encontrados no Brasil os gêneros Crolatus (cascavel), Lachesis (surucucu), Bothrops e 
Bothrocophias (conhecidas popularmente por jararacas). Já com relação à família Elapidae, estão presentes no país os gêneros Micrurus e Leptomicrurus, popularmente conhecidos como cobra coral ou coral verdadeira (COSTA; BÉRNILS, 2018). Até o momento, foram descritas 64 espécies de serpentes peçonhentas no Brasil, sendo 29 espécies de jararacas, 1 espécie de cascavel, 1 de surucucu e 33 espécies de corais verdadeiras (COSTA; BÉRNILS, 2018). Em caso de picadas por qualquer uma dessas serpentes, o tratamento mais eficaz é a aplicação hospitalar do soro antiofídico, que é específico para o gênero causador do acidente (BRASIL, 2001).

Algumas características podem facilitar a identificação de uma serpente peçonhenta como, por exemplo, a presença das fossetas loreais, que são dois orifícios localizados ligeiramente abaixo da linha que separa os olhos das narinas, e que tem a função de órgão termorreceptor, ajudando na localização das presas (FREITAS; SILVA, 2006). A fosseta loreal é encontrada em todas as espécies brasileiras pertencentes à família Viperidae, sendo assim de extrema importância para a rápida identificação destas serpentes que são responsáveis por cerca de 99\% dos acidentes no Brasil (CARDOSO et al., 2009). Já as serpentes da família Elapidae não apresentam fosseta loreal. Entretanto, uma forma de identificar esses ofídios é através da sua coloração externa, composta pelas cores vermelha, preta, branca ou amarela dispostas em tríades, formando anéis que circundam todo o corpo (ventre e dorso) (FREITAS; SILVA, 2006). Uma exceção a esta regra são as espécies pertencentes ao gênero Leptomicrurus, que apresentam cor uniforme preta no seu dorso, sem a presença de anéis e com manchas vermelhas ou amarelas na região ventral (CARDOSO et al., 2009).

Outro fator determinante para saber se uma serpente é peçonhenta ou não é através de sua dentição que pode ser áglifa, opistóglifa, proteróglifa e solenóglifa. Na dentição do tipo áglifa, presente nas serpentes não peçonhentas, o animal vai apresentar dentes maxilares anteriores e posteriores não sulcados, sem nenhuma adaptação para a inoculação de veneno na presa. Na dentição opistóglifa, um par de dentes maior que os outros está localizado na região posterior do maxilar da serpente. Esse par de dentes apresenta um sulco aberto que permite o escoamento da secreção produzida pelas glândulas de Duvernoy. Algumas serpentes com esta dentição são por vezes chamadas de semipeçonhentas, devido ao envenenamento leve causado por algumas espécies. Como exemplo de espécies dotadas de dentição opistóglifas temos algumas cobras verdes e cobras cipós, além de algumas falsas corais (FREITAS e 
SILVA, 2006; SERAPICOS e MERUSSE, 2006).

As serpentes consideradas peçonhentas e de importância médica apresentam dentições adaptadas para a inoculação do seu veneno, produzidas em duas glândulas específicas ligadas ao par de dentes anteriores do maxilar. Nas serpentes da família Elapidae (corais verdadeiras) a dentição é do tipo proteróglifa, onde temos um par de dentes fixo e localizado na região anterior e superior da maxila, ambos apresentando um canal interno para escoar o veneno dentro da presa. Na dentição solenóglifa, as serpentes também vão apresentar um par de dentes localizados na região anterior e superior da maxila, porém estes são móveis e bem desenvolvidos, além de apresentarem o canal interno para o completo escoamento do veneno. A dentição solenóglifa está presente nas espécies da família Viperidae, representada no Brasil pelas jararacas, cascavéis e surucucus (FREITAS e SILVA, 2006).

Diante da diversidade de serpentes encontradas no país, é importante que a população em geral seja capaz de reconhecer os gêneros peçonhentos que ocorrem em sua região e diferenciá-los daqueles que não representam perigo para a saúde humana. Como temos representantes das famílias Viperidae e Elapidae espalhados em todas as regiões do Brasil, entendemos o quão importante é aprender noções básicas a respeito desses animais, não só para os profissionais de saúde, que eventualmente poderão vir a lidar com os acidentados em seus ambientes de trabalho, mas também para a população em geral, que podem vir a ter contato com esses animais em seu dia a dia (CARDOSO et al., 2009). Noções essas que não se resumem apenas a identificação de possíveis espécies peçonhentas como comentadas acima, mas também noções de primeiros socorros e principalmente do que não se deve fazer em caso de acidentes, bem como questões relacionadas à profilaxia e sintomatologia (BRASIL, 2017a).

Outra informação de grande importância e que também deve ser compartilhada com a população se dá em relação à importância ecológica que essas serpentes possuem nas cadeias alimentares, tanto sendo presas como sendo predadores, bem como a importância do veneno desses animais para a fabricação do soro antiofídico e de outros medicamentos (MONACO; MEIRELES; ABDULLATIF, 2017).

\section{Atuação e importância do livro didático no ambiente escolar e o PNLD}

O início de uma atuação mais sistemática do livro didático dentro do ambiente escolar brasileiro remonta ao período imperial, com a criação do colégio Dom Pedro II no Rio de 
Janeiro em 1837, o qual era destinado a pessoas de uma elite econômica privilegiada. Esse colégio adotava um currículo com referência à educação e cultura europeia e, em particular, a sociedade francesa. Assim, os primeiros livros e manuais didáticos utilizados na época eram importados da França, traduzidos ou na linguagem original (SILVA, 2012). Desde então, o livro didático vem sofrendo adaptações às diversas mudanças de paradigmas, alterações nos programas de ensino, renovações de currículos e também às inovações tecnológicas, mas sendo mantido sempre como parte fundamental do processo de ensino aprendizagem na educação básica (SILVA, 2012). Citando LAJOLO (1996):

[...] o livro que vai ser utilizado em aulas e cursos, que provavelmente foi escrito, editado, vendido e comprado, tendo em vista essa utilização escolar e sistemática. Sua importância aumenta ainda mais em países como o Brasil, onde uma precaríssima situação educacional faz com que ele acabe determinando conteúdos e condicionando estratégias de ensino, marcando, pois, de forma decisiva, o que se ensina e como se ensina o que se ensina (LAJOLO, 1996, p.4).

Com sua inserção dentro do ambiente escolar, o livro didático deve atender a dois públicos, que são os alunos e professores. Com relação aos alunos, o livro deve permitir que os mesmos possam escolher qual o melhor método a ser usado para chegar à solução de um problema. Também deve aplicar conceitos relacionando-os com o cotidiano dos alunos e com outras áreas do conhecimento, mostrando assim que existe uma ligação entre eles e que o conteúdo não deve ser visto apenas de forma isolada. Enquanto que o livro do professor deve conter informações que o auxilie tanto no planejamento como no desenvolvimento das suas aulas, com propostas de aulas práticas e experimentais que tornem o conteúdo e as aulas mais atrativos, além de indicar bibliografias para que o professor possa se aprofundar no conteúdo que será trabalhado (ROMANATTO, 1997). Logo, percebemos que a escolha do livro didático que será trabalhado na escola é uma tarefa muito importante a ser realizada tanto pelos professores quanto por outros profissionais diretamente relacionados a essa. Logo:

O professor deve desenvolver saberes e ter competências para superar as limitações próprias dos livros, que por seu caráter genérico, por vezes, não podem contextualizar os saberes como não podem ter exercícios específicos para atender às problemáticas locais. É tarefa dos professores complementar, adaptar, dar maior sentido aos bons livros recomendados pelo MEC (NÚÑ̃Z et al., 2003, p.3).

Desde a criação do Programa Nacional do Livro Didático (PNLD) em 1985, o governo 
vem realizando periodicamente a análise dos livros adotados pelas escolas públicas, com o objetivo de melhorar essas obras que serão destinadas a alunos e professores do ensino fundamental e médio. Segundo o Ministério da Educação (BRASIL, 2017b) o objetivo do PNLD é avaliar e disponibilizar de forma gratuita não só os livros didáticos, mas também outros materiais que apoiem à prática educativa nas redes federais, estaduais, municipais e distritais de ensino, em todo o território brasileiro. As coleções, uma vez escritas em editais que são abertos pelo Ministério da Educação, passam por um processo de avaliação por profissionais de diferentes áreas. Caso aprovadas, essas coleções irão então compor o Guia Digital do PNLD (BRASIL, 2017c), que na verdade serve para guiar tanto os professores como os demais profissionais envolvidos no processo de escolha do LD a ser utilizado na escola pelos três anos seguintes.

\section{Metodologia}

O presente artigo se configura de forma qualitativa, documental e descritiva, utilizando-se como fonte de pesquisa as coleções aprovadas pelo Programa Nacional do Livro Didático (PNLD no triênio 2018 - 2020) conforme dispostas no quadro 1 abaixo. Os livros foram adquiridos mediante empréstimo junto a algumas escolas da rede estadual de ensino da cidade de Vitória de Santo Antão - PE.

Quadro 1 - Relação das coleções de livros de biologia destinados aos alunos do ensino médio e aprovados pelo Programa Nacional do Livro Didático (triênio 2018-2020).

\begin{tabular}{|c|c|}
\hline Livro 1 & $\begin{array}{l}\text { AMABIS, José Mariano; MARTHO, Gilberto Rodrigues. Biologia Moderna: } \\
\text { Amabis \& Martho. 1. ed. São Paulo: Moderna, } 2016 .\end{array}$ \\
\hline Livro 2 & $\begin{array}{l}\text { BIZZO, Nélio. Integralis - Biologia: Novas bases. 1. ed. São Paulo: IBEP, } \\
2016 .\end{array}$ \\
\hline Livro 3 & CÉSAR; SEZAR; CALDINI. Biologia. 12. ed. São Paulo: Saraiva, 2016. \\
\hline Livro 4 & $\begin{array}{l}\text { CATANI, André et al. Ser Protagonista - Biologia: Ensino médio. 3. ed. } \\
\text { São Paulo: Edições SM, } 2016 .\end{array}$ \\
\hline Livro 5 & $\begin{array}{l}\text { FAVARETTO, José. Biologia: Unidade e diversidade. 1. ed. São Paulo: FTD, } \\
2016 .\end{array}$ \\
\hline Livro 6 & $\begin{array}{l}\text { LINHARES, Sérgio; GEWANDSZNAJDER, Fernando; PACCA, Helena. } \\
\text { Biologia hoje. 3. ed. São Paulo: Ática, } 2016 .\end{array}$ \\
\hline Livro 7 & LOPES, Sônia; ROSSO, Sérgio. Bio. 3. ed. São Paulo: Saraiva, 2016. \\
\hline Livro 8 & MENDONÇA, Vivian. Biologia. 3. ed. São Paulo: AJS, 2016. \\
\hline Livro 9 & $\begin{array}{l}\text { OGO, Marcela; GODOY, Leandro. \#Contato Biologia. 1. ed. São Paulo: } \\
\text { Quinteto, } 2016 .\end{array}$ \\
\hline
\end{tabular}




\begin{tabular}{|l|l|}
\hline Livro 10 & $\begin{array}{l}\text { THOMPSON, Miguel; RIOS, Eloci. Conexões com a Biologia. 2. ed. São } \\
\text { Paulo: Moderna, 2016. }\end{array}$ \\
\hline
\end{tabular}
Fonte: Brasil (2017c).

Para analisarmos como o conteúdo sobre serpentes peçonhentas se encontra distribuído nos livros, bem como a presença de possíveis equívocos conceituais, foram estabelecidos alguns critérios detalhados a seguir: 1. Presença de imagens (conforme descrito no quadro 2); 2. Identificação do aparato (se o aparato inoculador de peçonha que no caso das serpentes são seus dentes se encontra descrito no texto); 3. Distribuição geográfica dos gêneros que são descritos no texto; 4. Importância ecológica desses animais dentro do ambiente natural em que ele vive; 5. Medidas profiláticas para evitar acidentes; 6. Sintomatologia, para os diferentes gêneros, em caso de acidente ofídico; 7. Primeiros socorros em caso de acidentes; 8. Equívocos conceituais (Se o livro apresenta algum conceito errado sobre ofidismo ou em relação a algum dos critérios acima descritos).

Em relação ao critério da presença de imagens, foi utilizada uma adaptação da metodologia de PERALES e JIMENEZ (2002), onde foram estabelecidas variáveis para a análise das imagens com base no trabalho de SILVA (2017), sendo elas: 1. Funcionalidade das ilustrações, 2. Relação com o texto principal e 3. Etiquetas verbais, conforme descritas no Quadro 2.

Quadro 2 - Variáveis utilizadas para a análise das imagens sobre serpentes nos livros didáticos de biologia aprovados pelo PNLD (2018-2020).

\begin{tabular}{|l|l|}
\hline Variáveis & Definição \\
\hline 1. Funcionalidade das ilustraçães & $\begin{array}{l}\text { A utilização consciente ou inconsciente, das } \\
\text { ferramentas gráficas como expressão de } \\
\text { ideias. }\end{array}$ \\
\hline Inoperantes & $\begin{array}{l}\text { Não apresentam nenhum elemento que possa } \\
\text { ser utilizado, sendo apenas de cunho } \\
\text { observacional. }\end{array}$ \\
\hline Elementos operativos Relação com o texto principal & $\begin{array}{l}\text { Apresentam elementos de representação } \\
\text { universais: dimensões, escalas, desenhos etc. }\end{array}$ \\
\hline Conotativa & $\begin{array}{l}\text { O tipo de relação estabelecida pelos autores } \\
\text { entre os textos e as imagens. }\end{array}$ \\
\hline Denotativa & $\begin{array}{l}\text { O texto descreve os conteúdos, porém não } \\
\text { menciona sua correspondência com os } \\
\text { elementos incluídos nas ilustrações. Nesse } \\
\text { caso se entende que essas relações são obvias } \\
\text { para o leitor. }\end{array}$ \\
\hline $\begin{array}{l}\text { O texto apresenta uma correspondência entre } \\
\text { os elementos da ilustração e os conteúdos } \\
\text { representados. }\end{array}$ \\
\hline
\end{tabular}




\begin{tabular}{|l|l|}
\hline 3. Etiquetas verbais & $\begin{array}{l}\text { São os textos incluídos nas ilustrações que } \\
\text { ajudam a interpretá-las. }\end{array}$ \\
\hline Sem etiquetas & A ilustração não contém texto nenhum. \\
\hline Relacional & $\begin{array}{l}\text { Textos que descrevem as relações entre os } \\
\text { elementos da ilustração. }\end{array}$ \\
\hline Normativas & $\begin{array}{l}\text { Letras ou palavras que identificam alguns } \\
\text { elementos da ilustração. }\end{array}$ \\
\hline
\end{tabular}

Fonte: Adaptado de PERALES E JIMENEZ (2002) e SILVA (2017).

\section{Resultados e Discussão}

Após a análise de todos os volumes das 10 coleções de livros de Biologia aprovados pelo PNLD (Quadro 1), observamos que o conteúdo sobre serpentes e acidentes ofídicos se encontra distribuído no volume 2 na grande maioria delas, sendo assim abordado no $2^{\circ}$ ano do Ensino Médio. Como exceções, temos a coleção "Biologia" de CÉSAR, SEZAR e CALDINI (Livro 3, quadro 1), cujo conteúdo se encontra distribuído entre os volumes 2 e 3, e a coleção “Conexões com a Biologia” de THOMPSON e RIOS (Livro 10, quadro 1), cujo conteúdo se faz presente no volume 3. Para fins de resultados e discussão, estes volumes serão tratados apenas pelos números dos livros, conforme apresentados no quadro 1.

Como podemos observar no Quadro 3 abaixo, embora contemplado em todas as coleções didáticas, em alguns livros o conteúdo analisado é apresentado de forma reduzida e insatisfatória (livro 1, 2, 9 e 10). Com relação aos critérios analisados, muitos deles são descritos dentro do conteúdo de répteis, onde são abordadas as características gerais tais como as morfológicas e fisiológicas, enquanto em outros livros alguns critérios são encontrados em uma página específica do livro intitulada como, por exemplo, "acidentes ofídicos", "serpentes peçonhentas", “As serpentes" e etc. Neste caso, geralmente é destacada toda a parte relacionada aos acidentes ofídicos junto com os tipos de dentição. Ainda com relação às dentições, estas foram descritas em nove dos dez livros analisados, com exceção do livro 1 (quadro 1). Na maioria dos livros $(2,3,4,5,6,7,8$ e 9) foi dada maior ênfase nas dentições áglifa e solenóglifa, sendo estas encontradas nas serpentes não peçonhentas e nas espécies da família Viperidae (jararacas, cascavéis e surucucus), respectivamente. Embora a dentição presente nas cobras corais (família Elapidae) seja do tipo proteróglifa e esta seja a forma mais eficaz de diferenciar as corais verdadeiras das corais falsas, esta dentição foi negligenciada em alguns livros (1, 4, 6 e 10).

Quadro 3- Critérios analisados sobre o conteúdo de serpentes nos livros didáticos aprovados pelo PNLD (20182020). A letra "P" representa presente e a "A" Ausente. 


\begin{tabular}{|c|c|c|c|c|c|c|c|c|c|c|}
\hline Crité & $\stackrel{-1}{0}$ & 光 & 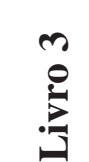 & $\stackrel{+}{\stackrel{0}{0}}$ & $\overbrace{0}^{n}$ & $\stackrel{0}{0}$ & ํㅗㄹ & 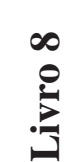 & $\stackrel{a}{0}$ & 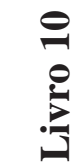 \\
\hline $\begin{array}{l}\text { Presença de } \\
\text { Imagens }\end{array}$ & $\mathrm{P}$ & $\mathrm{P}$ & $\mathrm{P}$ & $\mathrm{P}$ & $\mathrm{P}$ & $\mathrm{P}$ & $\mathrm{P}$ & $\mathrm{P}$ & $\mathrm{P}$ & $\mathrm{P}$ \\
\hline $\begin{array}{l}\text { Indicação do } \\
\text { Aparato no Texto }\end{array}$ & A & $\mathrm{P}$ & $\mathrm{P}$ & $\mathrm{P}$ & $\mathrm{P}$ & $\mathrm{P}$ & $\mathrm{P}$ & $\mathrm{P}$ & $\mathrm{P}$ & $\mathrm{P}$ \\
\hline $\begin{array}{l}\text { Distribuição } \\
\text { Geográfica no } \\
\text { Brasil }\end{array}$ & A & A & $\mathrm{P}$ & A & A & A & A & $\mathrm{P}$ & A & $\mathrm{P}$ \\
\hline $\begin{array}{l}\text { Importância } \\
\text { Ecológica }\end{array}$ & A & $\mathrm{A}$ & A & $\mathrm{P}$ & A & A & $\mathrm{A}$ & $\mathrm{P}$ & A & A \\
\hline $\begin{array}{l}\text { Medidas } \\
\text { Profiláticas }\end{array}$ & A & A & $\mathrm{P}$ & $\mathrm{P}$ & A & $\mathrm{P}$ & $\mathrm{P}$ & $\mathrm{P}$ & $\mathrm{P}$ & $\mathrm{P}$ \\
\hline Sintomatologia & $\mathrm{A}$ & $\mathrm{A}$ & $\mathrm{P}$ & $\mathrm{P}$ & $\mathrm{P}$ & $\mathrm{A}$ & $\mathrm{A}$ & $\mathrm{P}$ & $\mathrm{A}$ & $\mathrm{P}$ \\
\hline $\begin{array}{l}\text { Primeiros } \\
\text { Socorros }\end{array}$ & A & $\mathrm{A}$ & $\mathrm{P}$ & A & $\mathrm{P}$ & $\mathrm{P}$ & $\mathrm{P}$ & $\mathrm{P}$ & A & $\mathrm{P}$ \\
\hline $\begin{array}{l}\text { Equívocos } \\
\text { Conceituais } \\
\end{array}$ & A & A & $\mathrm{P}$ & A & A & A & $\mathrm{P}$ & A & A & $\mathrm{P}$ \\
\hline
\end{tabular}

Fonte: própria (2019)

Com relação à importância ecológica das serpentes, esta foi abordada apenas nos livros 4 e 8 (Quadro 3). Neles foi destacada a relevância desses animais nas teias alimentares e no controle da população de roedores. Em dois dos livros analisados, embora não tenha sido abordada a relevância ecológica do animal, foi relatado pelos autores a importância do veneno de algumas serpentes para o desenvolvimento de medicamentos. Em um deles (livro 3) o autor trouxe o tema "A jararaca e a hipertensão", enquanto no outro (livro 7) o tema abordado foi "Veneno da cascavel pode ser usado para combater câncer". Temas como estes nos LD são muito importantes para desmistificar a ideia de que as serpentes peçonhentas servem apenas para causar acidentes e por isso não devem ser conservadas.

A distribuição geográfica das serpentes foi abordada em 3 livros (Quadro 3), porém de forma insatisfatória. No livro 3 foi dado maior destaque na distribuição dos acidentes e menos na distribuição especifica de cada gênero de importância médica no Brasil. O livro não aborda, por exemplo, a distribuição das serpentes do gênero Micrurus, e no caso das cascavéis (Crotalus) apenas cita os nomes populares que elas são conhecidas nas regiões Norte, Centro e Sul do Brasil. Em relação a surucucu (Lachesis), apenas cita que elas estão distribuídas na Floresta Amazônica e Mata Atlântica. Já no livro 10 essa distribuição é focada apenas nas 
jararacas (Bothrops) e de forma equivocada, como melhor descrito abaixo em erros conceituais. Enquanto que no livro 8, é abordada a distribuição da surucucu nas regiões Amazônica e da Mata Atlântica e das jararacas com predomínio de distribuição nas regiões sul e sudeste do Brasil. Informações incompletas como estas, assim como a inexistência de qualquer informação em alguns livros, dificultam a compreensão do leitor tanto quanto aos gêneros de serpentes que são peçonhentas e, consequentemente, apresentam importância médica no Brasil, quanto a presença ou não destes animais na sua região.

Em relação às medidas profiláticas, estas são citadas em 7 das 10 coleções analisadas (Quadro 3) e em nenhum dos livros foram observados equívocos conceituais. Entretanto, em quatro livros (4, 6, 9 e 10) essas informações se apresentam de forma insatisfatória, apresentando apenas algumas poucas medidas profiláticas como, por exemplo, utilizar calçados adequados como botas de cano alto ao andar em regiões de mata ou campo e evitar mexer em buracos, amontoados de folhas etc. Já nos livros 3, 7 e 8, são apresentadas e melhores detalhadas as mesmas medidas abordadas pelos outros livros citados acima, mas também são citadas medidas como a importância de se proteger os predadores naturais das serpentes, o não acumulo de lixo ou material inútil perto das residências, a importância de se controlar a população de predadores etc. $\mathrm{O}$ detalhamento e o maior número de medidas profiláticas apresentadas nos livros 3, 7 e 8 nos levou a classifica-los quanto a este critério como satisfatórios.

Os primeiros socorros são considerados muito importantes para manter as funções vitais do acidentado e evitar o agravamento de seu estado até a chegada de assistência médica especializada. Ressaltando também que qualquer pessoa treinada poderá prestar esses primeiros socorros, desde que os conduza com calma, compreensão e confiança (BRASIL, 2003). Nos LD analisados, os primeiros socorros são bem enfatizados em 6 dos 10 livros analisados (quadro 3) e são apresentados sem nenhum equivoco conceitual e com instruções claras para o leitor. Além disso, os livros não só abordam os procedimentos corretos como também os procedimentos que não devem ser feitos em caso de acidentes, o que acaba sendo importante para evitar maiores complicações no quadro clinico do acidentado.

Os venenos de serpentes representam uma mistura complexa de 20 ou mais compostos diferentes, com cerca de $90 \%$ do seu peso seco representado por uma grande diversidade de peptídeos e proteínas biologicamente ativas, sobretudo enzimas, que difere consideravelmente nos diferentes gêneros de serpentes peçonhentas (STOCKER, 1990). Sendo assim, a 
sintomatologia desenvolvida pelo acidentado será o reflexo da composição do veneno inoculado e irá variar de acordo com o gênero da serpente causadora do acidente.

A sintomatologia dos acidentes foi citada em apenas 5 dos 10 livros avaliados (Quadro 3). Dentre eles, este critério foi melhor descrito no livro 3, pois além de citar a ação do veneno (hemorrágico, proteolítica, etc) dos 4 gêneros de importância médica, o livro também cita alguns sintomas decorrentes da ação desse veneno. Diferentemente do livro 3, nos livros 4, 5, e 10 são descritos poucos sintomas, sendo estes na grande maioria das vezes substituídos pelas ações específicas dos venenos, informando se o mesmo é neurotóxico, hemorrágico, miotóxico, etc. Com relação ao livro 10, este descreve apenas os sintomas relacionados ao envenenamento por jararaca (Bothrops).

Quanto às imagens, elas estão presentes em todos os livros, inclusive no primeiro, que não contempla nenhum outro critério (Livro 1, Quadro 3). As imagens representam principalmente os gêneros peçonhentos, porém também são retratados outros gêneros de serpentes. Com frequência aparecem imagens evidenciado a pele, a dentição solenóglifa, o destaque para a fosseta loreal, a diferença da cauda nos gêneros de importância médica da Família Viperidae, entre outros. Isso evidencia a importância das imagens para a identificação do aparato descrito no texto e até mesmo na identificação ou diferenciação de espécies ou gêneros que também estão sendo citados no texto.

Todos os dados referentes às imagens podem ser observados na Tabela 1. A maioria das imagens analisadas foi classificada como inoperante, apresentando só a imagem do animal e, sendo assim, apenas de cunho observacional. Também com frequência não são citadas no texto principal, o que as caracteriza na sua maioria como conotativas. Por fim, quase todas as imagens apresentaram etiquetas, sendo classificadas como relacionais. O maior número de imagens foi encontrado no livro 8, porém das 15 imagens presentes apenas 5 delas apresentavam elementos operativos (Tabela 1). No caminho oposto, o Livro 1 apresentou uma única figura, classificada como inoperante, denotativa e relacional (Tabela 1).

Tabela 1 - Análise das imagens sobre o conteúdo de serpentes nos livros didáticos aprovados pelo PNLD (20182020).

\section{LIVROS}

\begin{tabular}{llllllllllll}
\cline { 2 - 6 } & $\mathbf{1}$ & 2 & 3 & 4 & 5 & 6 & 7 & 8 & 9 & 10 \\
\hline
\end{tabular}

1. 


\begin{tabular}{|c|c|c|c|c|c|c|c|c|c|c|}
\hline $\begin{array}{l}\text { Funcionalic } \\
\text { das ilustrac }\end{array}$ & & & & & & & & & & \\
\hline Inoperantes & 1 & 2 & 4 & 2 & 1 & 1 & 6 & 10 & 7 & 3 \\
\hline Elementos & 0 & 5 & 8 & 1 & 4 & 2 & 6 & 5 & 0 & 0 \\
\hline
\end{tabular}

\section{Relação com o}

\section{texto principal}

\begin{tabular}{lllllllllll} 
Conotativa & 0 & 0 & 12 & 0 & 5 & 0 & 7 & 11 & 7 & 3 \\
Denotativa & 1 & 7 & 0 & 3 & 0 & 3 & 5 & 4 & 0 & 0 \\
\hline
\end{tabular}

\section{Etiquetas}

\section{verbais}

\begin{tabular}{lllllllllll} 
Sem etiqueta & 0 & 0 & 0 & 0 & 0 & 0 & 0 & 3 & 0 & 0 \\
Relacional & 1 & 7 & 12 & 3 & 5 & 3 & 12 & 12 & 7 & 3 \\
Normativas & 0 & 0 & 0 & 0 & 0 & 0 & 0 & 0 & 0 & 0 \\
\hline Total de Imagens & 1 & 7 & 12 & 3 & 5 & 3 & 12 & 15 & 7 & 3 \\
\hline
\end{tabular}

Fonte: própria (2019).

As imagens são elementos de grande importância para a apresentação dos conceitos relacionados às ciências naturais, tanto na forma de desenhos e ilustrações mais simples quanto com o emprego de técnicas mais sofisticadas de produção (BRUZZO, 2004). Se uma imagem é apresentada no livro de forma adequada, ela terá a função de melhorar a compreensão do texto, construindo assim uma relação de conectividade (RIBEIRO, 2011). Dessa forma, uma maior atenção por parte dos autores dos LD na forma de apresentar as figuras e relaciona-las ao texto pode contribuir fortemente para o aprendizado dos alunos. Com relação ao tema por nós trabalhado, é importante reforçar a relevância da presença de imagens com legendas e textos relacionais das principais serpentes peçonhentas do Brasil e suas respectivas distribuições geográficas, além das estruturas capazes de diferencia-las das serpentes não peçonhentas, como dentições associadas e fosseta loreal.

Com relação aos erros conceituais relacionados ao tema serpentes, estes foram encontrados em apenas 3 livros. Em dois deles, livros 3 e 7 (quadro 1), foram encontradas as seguintes informações com relação a dentição áglifa:

"Essas serpentes são chamadas de áglifas ( $\mathrm{a}=$ sem; glifo = presa $)$, pois todos os seus dentes apresentam a mesma morfologia.” (CÉSAR; SEZAR; CALDINI; 
2016, p. 260).

“[...] áglifa: não há dentes inoculadores de veneno, e todos os dentes são iguais." (LOPES; ROSSO; 2016, p.248).

Em ambos os trechos, os autores afirmam que as serpentes com dentição áglifa apresentam todos os dentes iguais ou com a mesma morfologia. Entretanto, segundo CARDOSO et al. (2009), página 48: “[...] Dentro desta categoria distinguem-se variadas condições, como homodonte (com todos os dentes iguais) e heterodonte (com alguns dentes alongados)".

Entretanto, o mais importante erro conceitual foi encontrado no livro 10 (quadro 1), sendo este relacionado com a distribuição geográfica das jararacas, como mostra o trecho a seguir:

“As jararacas habitam florestas e zonas degradadas, desde a Bahia até o Rio Grande do Sul". (THOMPSON; RIOS; 2016, p. 278).

Ao contrário do descrito pelos autores, as serpentes do principal gênero de jararacas, o gênero Bothrops, apresentam uma ampla distribuição geográfica, sendo encontrada em todos os biomas e regiões do território brasileiro. Como exemplos de jararacas em regiões não citadas pelo autor temos as Bothrops atrox, conhecida popularmente por jararaca-do-norte, principal responsável por acidentes na região norte do país, incluindo a Floresta Amazônica. Também a Bothrops erythromelas, conhecida popularmente por jararaca-da-seca, amplamente distribuída na região Nordeste e bastante comum na caatinga esta serpente é responsável pela grande maioria dos acidentes em diversos estados da região (CARDOSO et al., 2009).

\section{Conclusões}

A análise dos livros de biologia, aprovados pelo PNLD para o triênio de 2018 a 2020, revelou que o conteúdo de serpentes ainda se faz presente nas coleções de uma forma que não contempla a grande diversidade e importância destes animais para a biologia e para a saúde pública. Em muitos livros, os autores parecem não se preocupar com temas relacionados à importância ecológica, fazendo com que esses animais sejam vistos apenas como causadores de acidentes. Outro ponto importante é a ausência da correta distribuição geográfica das 
serpentes peçonhentas. Visto que alguns gêneros ou espécies tem distribuição geográfica restrita à determinadas regiões, seria importante para o aluno conhecer quais estão presentes em sua localidade.

Dentre as 10 coleções aprovadas pelo PNLD, os livros 3 e 8 foram considerados os mais indicados para se trabalhar o conteúdo de serpentes em sala de aula. Muito embora o livro 3 apresente um equívoco conceitual, relacionado a dentição áglifa, e o livro 8 apresente o maior número de imagens inoperantes e conotativas, estes livros abordaram o maior número de critérios avaliados por nós. Vale ressaltar ainda que o livro 1 não apresentou nenhum conteúdo especifico de relevância relacionado ao tema serpentes e acidentes ofídicos.

Diante do conteúdo escasso ou insatisfatório em algumas coleções selecionadas pelo PNLD, é de suma importância que o professor análise bem o LD adotado por sua escola antes de trabalhar os temas serpentes e acidentes ofídicos, evitando assim a disseminação dos erros conceituais citados.

Por fim, com este trabalho esperamos buscar a atenção dos autores das obras avaliadas para a inclusão ou melhoria do conteúdo relacionado a acidentes ofídicos, uma vez que este continua sendo um grave problema de saúde pública no Brasil.

\section{Referências}

BERGMANN, A.G.; DOMINGUINI, L. Análise do Conteúdo Serpentes nos Livros Didáticos de Ciências do $7^{\circ}$ Ano do Município de Blumenau. Revista Brasileira de Pesquisa em Educação em Ciências, v. 15, n. 2, p. 259-273, 2015.

BORGES, R. C.; OLIVEIRA, A.; COSTA, R. M. C. Serpentes peçonhentas: identificação e procedimentos em acidentes - uma análise dos livros didáticos do Ensino Fundamental e Médio. Revista de Estudo e Pesquisa em Educação, v. 5, n. 1, p. 121-133, 2003.

BRASIL. Ministério da Saúde, Funasa. Manual de Diagnostico e Tratamento por Animais Peçonhentos. Brasília: MS, 2001.

BRASIL. Manual de Primeiros Socorros. Rio de Janeiro: Fundação Oswaldo Cruz, 2003, 170p.

BRASIL. Ministério da Saúde. Acidentes por animais peçonhentos. Brasília: MS, 2017a. Disponível em: http://portalms.saude.gov.br/saude-de-a-z/acidentes-por-animais-peconhentos. Acesso em: 22 ago.2019.

BRASIL. Ministério da Educação. PNLD. Brasília: DF, 2017b. Disponível em: http://portal.mec.gov.br/pnld/apresentacao. Acesso em: 08 ago.2019. 
BRASIL. Ministério da Educação. PNLD 2018: biologia - guia de livros didáticos - Ensino Médio. Brasília, DF: Ministério da Educação, Secretária de Educação Básica, 2017c.

BRASIL. Ministério da Saúde. Casos de acidentes por serpentes. Brasil, Grandes Regiões e Unidades Federadas. 2000 a 2018*.Brasília: MS, 2019a. Disponível em: http://www.saude.gov.br/saude-de-a-z/acidentes-por-animais-peconhentos\#epidemiologia. Acesso em: 05 ago.2019.

BRASIL. Ministério da Saúde. Óbitos por animais serpentes. Brasil, Grandes Regiões e Unidades Federadas. 2000 a 2018*. Brasília: MS, 2019b. Disponível em: http://www.saude.gov.br/saude-de-a-z/acidentes-por-animais-peconhentos\#epidemiologia. Acesso em: 05 ago.2019.

BRUZZO, C. Biologia: educação e imagens. Educação e Sociedade, Campinas, v. 25, n.89, p. 1359-1378, 2004.

CARDOSO, J. L. C. et al. Animais peçonhentos no Brasil: biologia, clínica e terapêutica dos acidentes. 2.ed. São Paulo: Sarvier, 2009.

Costa, H.C.; Bérnils, R.S. Répteis do Brasil e suas Unidades Federativas: Lista de espécies. Herpetologia Brasileira, v.7, n.1, p. 11-29, fev. 2018. Disponível em: http://sbherpetologia.org.br/wp-content/uploads/2016/10/lista-de-repteis-2018-2.pdf. Acesso em: 23 ago. 2019.

FRACALANZA, H.; MEGID NETO, J. O livro didático de ciências no Brasil. 1.ed. Campinas: Komedi, 2006.

FREITAS M. A; SILVA T.F.S. Guia ilustrado: animais venenosos e peçonhentos no Brasil. Porto Alegre: Editora União Sul-Americana de Estudos da Biodiversidade, 2006.

GUIMARÃES, L. A. F. Acidentes por animais peçonhentos: identificação dos erros conceituais contidos nos livros didáticos dos ensinos fundamental e médio. 2010. Dissertação (Mestrado em Biologia Animal) - Universidade de Brasília, Brasília, 2010.

LAJOLO, M. Livro didático: um (quase) manual de usuário. Em Aberto, Brasília, ano 16, n. 69 ,jan/mar, 1996.

MONACO, L.M.; MEIRELES, F.C.; ABDULLATIF, M.T.G.V. Animais venenosos: serpentes, anfíbios, aranhas, escorpiões, insetos e lacraias. 2.ed.rev.ampl. São Paulo: Instituto Butantan, 2017. Disponível em: http://publicacoeseducativas.butantan.gov.br. Acesso em: 07 ago.2019.

NICOLA, J. A.; PANIZ, C. M. A importância da utilização de diferentes recursos didáticos no ensino de biologia. Infor, Inov. Form., Rev. NEaD-Unesp, São Paulo, v. 2, n. 1, p.355381, 2016. ISSN 2525-3476. Disponível em: https://ojs.ead.unesp.br/index.php/nead/article/view/InFor2120167. Acesso em: 23 ago.2019.

NÚÑEZ, I. B. et al. A seleção dos livros didáticos: um saber necessário ao professor. O caso 
do ensino de ciências. Revista Iberoamericana de Educación. Madrid, 2003.

NUÑEZ, I. B. et al. O livro didático para o ensino de ciências. Selecioná-los: um desafio para os professores do ensino fundamental. In: ENCONTRO NACIONAL DE PESQUISA EM EDUCAÇÃO EM CIÊNCIAS., 3., 2001. [s.1.], Anais... [s.1.], 2001.

PERALES, F. J.; JIMÉNEZ, J. D. Las ilustraciones en la enseñanza-aprendizaje de las ciencias. Análisis de libros de texto. Enseñanza de las ciencias. Barcelona, v. 20, n. 3, p. 369-386, 2002.

RIBEIRO, E. N. A imagem na relação de expressão com o texto escrito - contribuições da áudio-descrição para a aprendizagem de educandos surdos. 2011. 174 f. Dissertação (Mestrado em Educação) - Universidade Federal de Pernambuco, Recife, 2011.

ROMANATTO, M. C. O livro didático: alcances e limites. [s.1.], 1997.

SANDRIN, M. F. N.; PUORTO, G.; NARDI, R. Serpentes e acidentes ofídicos: um estudo sobre erros conceituais em livros didáticos. Investigações em Ensino de Ciências, Porto Alegre, v. 10, n. 3, p. 281-298, 2005.

SANTOS, A. P. Análise dos conteúdos sobre animais peçonhentos nos livros didáticos de biologia do ensino médio, 2018. Trabalho de conclusão de curso (Licenciatura em ciências biológicas) - Universidade Federal de Pernambuco, Vitória de Santo Antão, 2018.

SERAPICOS, E.O.; MERUSSE, J.L.B. Morfologia e histoquímica das glândulas de Duvernoy e supralabial de seis espécies de colubrídeos opistoglifodontes (Serpentes, Colubridae). Pap. Avuls Zool. São Paulo, v. 46, n. 15, p. 187-195, 2006.

SILVA, E.S.; BOCHNER, R.; GIMÉNEZ, A.R.M. O ensino das principais características das serpentes peçonhentas brasileiras: avaliação das literaturas didáticas no Ensino Fundamental do Município do Rio de Janeiro. Educar em Revista, Curitiba, n. 42, pp. 297-316, out./dez. 2011.

SILVA, M. A. A fetichização do livro didático no Brasil. Educação e Realidade, Porto Alegre, v. 37, n. 3, p. 803-821, dez., 2012.

SILVA, M. J. F. As Pteridófitas nos livros de história natural de Cândido de Mello Leitão nos anos de 1930. 2017. 19f. Trabalho de conclusão de curso (Monografia) - Licenciatura em ciências biológicas, Universidade Federal de Pernambuco, Vitória de Santo Antão, 2017.

STOCKER, K.F. Composition of Snake Venoms. In: Stocker, K.F. Medical use of snake proteins, CRC Pess., Boca Raton, V. 2. P. 33-57, 1990. 